Florida International University FIU Digital Commons

7-22-1998

\title{
The effect of self-operated prompts on leisure participation by persons with mental retardation
}

Tanya Michele Camper

Florida International University

DOI: $10.25148 /$ etd.FI14052552

Follow this and additional works at: https:// digitalcommons.fiu.edu/etd

Part of the Recreational Therapy Commons

\section{Recommended Citation}

Camper, Tanya Michele, "The effect of self-operated prompts on leisure participation by persons with mental retardation" (1998). FIU Electronic Theses and Dissertations. 1988.

https://digitalcommons.fiu.edu/etd/1988 


\section{FLORIDA INTERNATIONAL UNIVERSITY \\ Miami, Florida}

THE EFFECT OF SELF-OPERATED PROMPTS ON LEISURE

PARTICIPATION BY PERSONS WITH MENTAL RETARDATION

A thesis submitted in partial satisfaction of the

requirements for the degree of

MASTER OF SCIENCE

IN

PARKS AND RECREATION MANAGEMENTI

RECREATIONAL THERAPY

by

Tanya Michele Camper

1998 
To: Acting Dean, Robert Vos College of Education

This thesis, written by Tanya Michele Camper, and entitled, "The Effect of SelfOperated Prompts on Leisure Participation by Persons with Mental Retardation," having been approved in respect to style and intellectual content, is referred to you for judgement.

We have read this thesis and recommend that it be approved.

Daniel Dustin

Robert Wolff

Michael Brady, Major Professor

Date of Defense: July 22,1998

The thesis of Tanya Michele Camper is approved.

Acting Dean, Robert Vos

College of Education

Dr. Richard L. Camphell

Dean of Graduate Studies

Florida International University, 1998 
COPYRIGHT @ 1998 by Tanya Michele Camper

All rights reserved. 
For Robbin, the one who inspires me each and every day. This thesis would not have been completed without your love, encouragement, and patience. 


\section{ACKNOWLEDGEMENTS}

First, I would like to thank my loving parents, Ethan and Diana, for their love and support and for always encouraging me to follow my dreams. I would also like to thank my very special friend and research partner, Barbara Rucki, for her loyalty, continued support and guidance.

Many thanks to Liz Lussier, Countess Chapman, Cheri O'Jean and the wonderful staff at Sunrise Community, Inc. Their assistance and support was instrumental in the completion of this thesis. Also, I would like to thank Gary Nolan for his very generous assistance in creating my prompting tapes.

I would also like to express my gratitude to Dr. Thomas Skalko for inspiring me to further pursue my education in the field of Recreational Therapy. Also, I would like to thank all those individuals who have helped me throughout the past two years of my graduate career.

Finally, I would like to express my gratitude to my three committee members for all their assistance. My most sincere thanks goes to my major professor, Dr. Michael Brady for his endless hours of assistance and support. A special thanks to Dr. Robert Wolff and Dr. Daniel Dustin for their support, guidance and encouragement. 


\section{ABSTRACT OF THE THESIS \\ THE EFFECT OF SELF-OPERATED PROMPTS ON LEISURE \\ PARTICIPATION BY PERSONS WITH MENTAL RETARDATION \\ by}

Tanya Michele Camper

Florida International University, 1998

Miami, Florida

Professor Michael Brady, Major Professor

The use of permanent prompts for individuals with severe disabilities has been shown to be effective in acquiring new skills, improving the accuracy and maintenance of existing skills, and in eliminating the need for trainer prompts. However, this technology has not been evaluated for its potential impact in promoting leisure participation. In this study, two men with mental retardation were administered auditory and/or visual prompts to investigate their effect on increasing participation in a leisure activity. In addition, their performance was evaluated to establish whether continuous versus intermittent schedules of the prompts would influence participation. The data were collected using a partial interval observation system and evaluated using a multiple baseline and an alternating treatment design. While both men increased their participation modestly in the leisure activity, there was no substantial difference between the two prompting schedules. 
CHAPTER

PAGE

I. INTRODUCTION

1

Self-Management Strategies

Purpose of the Study

Research Questions

II. METHOD

9

Participants

Leisure Tasks and Activities

Procedures

Experimental Design

Behavioral Measures

III. RESULTS

Interobserver Agreement

Results of Research Question \#1

Results of Research Question \#2

IV. DISCUSSION

24

Limitations of Study

Practical Implications

Future Recommendations for Research

LIST OF REFERENCES

32

APPENDIXES

36 


\section{Chapter 1}

\section{Introduction}

The pursuit of leisure experiences by persons with disabilities has often been available only in segregated programs, with either solitary or family-oriented participation. However, the current emphasis of services for persons with disabilities is on the normalization and independence of their experiences. This infers that leisure participation will involve a strong community component. The term "leisure" is described as the person's perception that he or she is free to choose to participate in meaningful, enjoyable, and satisfying experiences (Dattilo \& Schleien, 1994). Participation in leisure experiences allows one the opportunity to express talents, demonstrate capabilities, achieve one's potential, and have pleasing and enjoyable experiences (Dattilo \& Schleien, 1994).

According to the American Therapeutic Recreation Association (1987), therapeutic recreation places particular emphasis on the provision of treatment services that improve functioning and independence, and on the provision of leisure resources and opportunities that improve health and well being. $A$ positive leisure experience is a major factor in improving quality of life and opportunities for self-development and self-expression (Peterson \& Gunn, 1984). Leisure pursuits are vital in contributing to the quality of life of individuals with and without disabilities.

The independent living movement for individuals with disabilities has led many individuals with severe disabilities to reside in community-based group homes, supervised apartments, and even in supervised independent residences. 
The philosophical driving force of the movement for community integration of individuals with disabilities is based on the principle of normalization, which stresses the delivery of services in environments and under circumstances that are as culturally normal as possible (Wolfensberger, 1972). "Community living encompasses the integration of individuals with disabilities into the community and addresses the social, recreational, vocational, and/or educational needs for individuals in that community" (Nisbet, Clark, \& Covert, 1991, p. 117). Litigation, legislation, and advocacy for the independent living movement has been driven by parents and consumers (Novak, \& Heal, 1980, Nisbet et al., 1991). Schultz, Vogelsberg, and Rusch (1980) stressed that to successfully integrate people with severe disabilities into community settings, they must be provided the opportunity to learn functional skills that enable them to live as independently as possible.

Bercovici (1983) reported that community living experiences sometimes mirror the most negative aspect of institutional living, including group treatment, isolation, and unoccupied free time. This results in a lowered quality of life for many people with mental retardation in spite of the richer opportunities available in a typical community. One possible explanation for the poor quality of life in some community living arrangements is the inadequacy or absence of leisure services (Hoover, Wheeler, \& Reetz, 1992). Hoover et al. noted that consumers with mental retardation often lack information regarding their personal choices; these choices are essential to the overall quality of their leisure experiences. A leisure satisfaction scale was developed by Hoover et al.; the instrument was designed to present data on areas of satisfaction and dissatisfaction among 
adults with mental retardation living in the community. Results of this study showed that quality of life appears to be limited to the number of available options and accessibility, which include transportation and accessories.

Community agencies generally impose limitations and restrictions on individuals' options, which did produce lower satisfaction scores. The authors also noted that when program planners require individuals to participate in activities against their will, these individuals lose an important degree of self-determination, an important component in their quality of life.

Although individuals with severe disabilities may live more independently in the community and acquire competitive or supported employment, their quality of life and normalization may be jeopardized if they do not have the training and opportunity to use free time. The term free time may be defined as an individuals' unobligated time, time away from work and other responsibilities. Individuals with severe disabilities often have an excess of free time and may not use their free time in constructive ways that provide enjoyment, pleasure, and satisfaction; others may use their free time in ways that are stigmatizing (Rynders \& Schleien, 1991; Wehman \& Schleien, 1981). Browder and Cooper (1994) attribute the nonconstructive use of free time for individuals with disabilities as often due to underdeveloped leisure skills.

Dattilo (1991) noted that unoccupied free time, limited participation in community recreation, restricted awareness of viable leisure options, and lack of skills necessary to participate in a range of in-home and community leisure activities are concerns frequently discussed in the literature regarding individuals 
with severe disabilities. When such individuals do not use their free time well, professionals exclude them from further opportunities for leisure activities because they assume that they are unable to perform and complete skill sequences independently and in correct order (Ford, Brown, Pumpian, Baumgart, Nisbet, Schroeder, \& Loomis, 1984). Professionals should prepare individuals with severe disabilities for leisure in a way that yields personal rewards and enables them to contribute to the life of the community in which they live (Dattillo, 1991). The professional challenge in assisting individuals with severe disabilities involves removing barriers to participation while providing opportunities to develop skills, awareness and understanding needed to choose freely to participate in leisure experiences (Dattilo \& Schleien, 1994).

The opportunity for these individuals to make choices is important because it can foster independence, provide a sense of control, and, therefore, improve the quality of their lives. Shevin and Klein (1984) discussed the importance of choice making as a skill for persons with severe disabilities, and stressed that learning to make appropriate choices is essential in achieving independence and a positive quality of life. In a study conducted to determine quality of life differences between adults with and without disabilities, Sands and Kozleski (1994) concluded that the degree of choice which adults with disabilities were able to exercise was significantly limited when compared to adults without disabilities. The study also noted that individuals with disabilities rated themselves as having low to moderate independence, and were dissatisfied with the frequency and variety of their community leisure activities. Therefore, it is 
important for professionals to recognize the need for personal choice, input, and self-determination in the area of leisure for individuals with severe disabilities (Hoover et al. 1992).

\section{Self-Management Strategies}

Many individuals with severe disabilities have difficulty directing their own lives and often have limitations in meeting age appropriate and cultural group standards in social responsibilities and personal independence (Grossman, 1983). It is often necessary for individuals with severe disabilities to require trainer assistance to assist and support all daily living tasks. Brady (1985) noted that there are a number of problems that may occur as a result of using various levels of assistance, which include the absence or availability of priming or total assistance in natural environments, the over use of assistance which may lead to dependency, and the incorrect use of fading procedures by trainers once the individual has learned the new skill. Self-management strategies may provide an opportunity to promote self-direction and choice among individuals with certain types of moderate and severe disabilities (Agran \& Martin, 1987; Bambara \& Ager, 1992; Browder \& Shapiro, 1985). Successful and continued functioning in a variety of environments can be hindered if persons are unable to maintain their own behaviors without the use of external assistance (Ferretti, Cavalier, Murphy, \& Murphy, 1993). Self-management strategies have been shown to reduce the need for external management by others, including paid staff members, by placing an individual in a position of control over his or her own environment. 
Self-management strategies also facilitate the maintenance and generalization of skills (Berg, Wacker, \& Flynn, 1990).

An example of the benefits of self-management strategies can be seen in a study conducted by Lovett and Haring (1989). They examined the effects of self-management techniques on the daily living activities of adults with mental retardation. Participants in their study received only instructions and training in self-recording, or various types of self-management techniques. The results of their study indicated that individuals with mental retardation could improve the self-direction and completion of daily living activities when taught to use various self-management strategies.

One type of self-management strategy involves adding cueing procedures to an individual's task. The use of cueing procedures during self-instruction for example, has the potential to allow an individual to perform tasks without the assistance of a trainer (Browder \& Shapiro, 1985). Cueing procedures may be defined as the use of some type of prompt that assists the individual to complete a certain task. Many individuals with severe disabilities have difficulty or are unable to generalize or maintain their performance in many daily living, vocational, and recreational tasks without the assistance of these prompts. Two self-operated prompting strategies that have proven successful for individuals with severe disabilities are the use of picture prompts and auditory prompts.

Picture prompts have been used to teach vocational tasks (Sowers, Rusch, Connis \& Cumming, 1980; Wacker \& Berg, 1983; Wacker, Berg, Berrie, \& Swatta, 1985), daily living skills (Thinesen \& Bryan, 1981), and food preparation 
tasks (Johnson \& Cuvo, 1981; Martin, Rusch, James, Decker \& Trytol, 1982).

The results of the study conducted by Wacker et al. 1985, indicated that although all students required many training sessions to learn the first sequence of a complex vocational or daily living task with the use of picture cues, they were able to generalize their use of the pictures across settings without additional training.

Auditory prompts have been used to teach daily living skills (Alberto, Sharpton, Briggs \& Stright, 1986; Briggs, Alberto, Sharpton, Berlin, McKinley \& Ritts, 1990; Tyler-Trask, Grossi, \& Heward, 1994), and to improve the accuracy and fluency of vocational tasks (Davis, Brady, Williams, \& Burta, 1992). For example, Alberto et al. (1986) used self-operated auditory prompts to teach students with severe disabilities daily living and vocational skills through the use of a Walkman-type recorder delivering auditory, step by step cues, without the direct intervention of a trainer. Davis et al. (1992) utilized auditory prompts to increase task fluency (fluency is defined in this study as a combination of normative speed and accuracy) of vocational tasks, showing that this use of a permanent prompting system can eliminate the need for trainer prompts to achieve and maintain fluency.

The use of auditory prompts in conjunction with picture prompts has been shown to be successful in teaching the completion of daily living skills (Mechling \& Gast, 1997). These self-operating prompting strategies have been successful in the instruction and acquisition of new skills, demonstrating maintenance of skills, and providing the individual with some degree of independence. 


\section{Purpose of the Study}

Although prompting strategies have been used successfully to acquire and maintain vocational tasks and daily living skills, no study has specifically investigated the use of self-operated prompts in promoting participation in leisure activities. The purpose of this study was to apply a permanent prompting technology to outcomes specifically addressed by the recreational therapy profession. This study was designed to explore the effects of taped prompts (audio and/or visual) on participation levels in leisure activities by individuals with moderate to severe disabilities.

\section{Research Questions}

Specifically, the following two questions were addressed:

1. Will the use of self-operated auditory and/or visual prompts increase the participation in a leisure activity by individuals with mental retardation?

2. Will alterations in the timing of the prompt schedules affect participation levels? 
Chapter 2

Method

\section{Participants}

Two men with severe mental retardation were selected to participate in the study. Both resided in a group home and participated in a sheltered workshop program run by Sunrise Community, Inc., a local organization that served individuals with developmental disabilities. Participants were recommended by their counselors and group home director, and each man agreed to participate. Consent was also obtained from a parent or legal guardian. To respect the anonymity of the two men, they were provided with pseudonyms.

Criteria for participation included:

1. Demonstration of the necessary skills to participate in a leisure activity (riding a stationary bike) when prompted by a trainer;

2. Dependence on trainers for instructions or stimulus control over the activity;

3. An expressed interest to participate in the study after being provided an explanation of procedures;

4. Generalized compliance on task performance.

Marc, 37 years old, was nonverbal and had difficulty expressing himself; he used a communication board to express basic desires. George, 42 years old, had a history of disruptive behavior at home and at work including screaming, pacing and hitting objects. The two individuals selected to participate had varying levels of IQ and adaptive behaviors. Specific characteristics for each participant are found in Table 1. 
Table 1.

Participant Characteristics

\begin{tabular}{|c|c|c|c|c|}
\hline $\begin{array}{c}\text { Participant } \\
\text { (Age) }\end{array}$ & Diagnosis & $\begin{array}{l}\text { Standard } \\
\text { Scores }\end{array}$ & Medication & Residence \\
\hline $\begin{array}{l}\text { GEORGE } \\
(42)\end{array}$ & $\begin{array}{l}\text { Mental } \\
\text { Retardation } \\
\text { Hypothyroidism } \\
\text { Optic Atrophy }\end{array}$ & $\begin{array}{l}\text { Stanford Binet: } \\
\text { Intellignce IQ:23 } \\
\text { Mental Age: } 3-5 \\
\text { Social Quotient: } 26 \\
\text { Adaptive Functioning: } \\
6.5\end{array}$ & $\begin{array}{l}\text { Tegretol } \\
\text { Mellaril } \\
\text { Ativan } \\
\text { Synthroid } \\
\text { Tablets }\end{array}$ & $\begin{array}{l}\text { Family Home } \\
\text { (birth-20) } \\
\text { Institution } \\
\text { (20-26) } \\
\text { Group Home } \\
\text { (26-Present) }\end{array}$ \\
\hline $\begin{array}{l}\text { MARC } \\
(37)\end{array}$ & $\begin{array}{l}\text { Mental } \\
\text { Retardation } \\
\text { Seizure Disorder }\end{array}$ & $\begin{array}{l}\text { Stanford Binet: } \\
\text { Intelligence IQ: } \downarrow 20 \\
\text { Mental Age: } 19 \text { mo. } \\
\text { Social Quotient: } 10 \\
\text { Adaptive Functioning: } \\
2-1\end{array}$ & $\begin{array}{l}\text { Tegretol } \\
\text { Mellaril }\end{array}$ & $\begin{array}{l}\text { Family Home } \\
\text { (birth- 9) } \\
\text { Institution } \\
\text { (9-26) } \\
\text { Group Home } \\
\text { (26-Present) }\end{array}$ \\
\hline
\end{tabular}

\section{Leisure Tasks and Activities}

The specific leisure activity evaluated in this study was selected and agreed upon by the participants and the researcher. The leisure activity selected was riding a stationary bike at each man's residence; this activity was regularly available and was identified by Marc and George as a preferred activity. The methods used to assess preferred leisure activities included consulting the individual's behavior management plan, asking staff and family members, making observations, and providing the individual with a pictorial assortment of potential leisure activities to choose from. Prior to the study, Marc and George were trained on the skills necessary to ride the stationary bike. The amount of training and practice sessions varied depending on each participant's skill level. Each participant was provided an opportunity to choose a preferred musical tape for use in the study. 


\section{Procedures}

The study employed a comparison of (a) pre-study assessment,

(b) baseline/ no music, (c) baseline/music only, (d) auditory prompt intervention and, (e) auditory plus visual prompt intervention (for George only).

Pre-study assessment. Prior to the study, both men were evaluated with regard to their efficiency in the use of headphones and tape players. Specifically, they were evaluated to determine whether they would:

1. wear headphones and tape players;

2. operate on and off buttons; and

3. maintain volume at a given level.

The participants were then trained by the researcher to use the audio equipment in the proper sequence.

Each participant was instructed to select a popular music tape based on his familiarity and preference for use in the study. Each participant was told that he could listen to the tape while riding the stationary bike. The methods used to assess the preferred music included consulting staff and family members, and the provision of an assortment of potential music. Marc was able to express his preference of music by Gloria Estefan, and one of his own tapes of this artist was used to create two prompting tapes based on the prompting schedules. For George, caregivers were unable to express an exact music preference but identified his preference of listening to a contemporary rock radio station. Various songs were selected and taped from the preferred radio station to create 
his prompting tape. The participants' tapes were made by inserting auditory prompts based on the two prompting schedules.

In addition to the audiotapes, a video prompting tape was used with George. To create the video prompting tape, five minutes of video was taken of George riding the stationary bike. The five-minute video was then duplicated to create a 15-minute video. Included in the 15 minutes was video of George riding the bike dubbed with auditory prompts alternating with a blank blue screen. Two videotapes were created based on the two prompting schedules.

In addition to using the tape player, George was instructed and evaluated concerning his efficiency and use of a television and VCR. Specifically, he was evaluated to determine whether he would:

1. operate the on and off buttons of a television and VCR;

2. operate the play button on the VCR; and

3. maintain the volume of the television at a given level.

George was trained by the researcher in the proper steps and procedures for handling the equipment. In addition, a secondary researcher assisted in instruction and data collection during the sessions.

Baseline no-music. During the first baseline of no music, both men performed the task without headphones, music, or prompts. No trainer prompts were delivered.

Baseline music only. During the second baseline, Marc and George performed the task wearing headphones with their chosen music without any prompts. No trainer prompts were delivered during this condition. 
Prompt intervention. During the auditory prompt condition, the participants listened to their individual tapes with the music and the auditory prompts inserted. The auditory prompts were inserted so that each tape used the following sequence throughout the tape: music for 12 seconds; a three-second pause; and the auditory prompt. No trainer prompts were delivered during this condition. In addition to the auditory prompts, a visual prompt condition was added for George. George listened and watched a videotape of himself riding the bike with auditory and visual prompts inserted onto the videotape. The audio and visual prompts were inserted so that each videotape used the following sequence throughout the tape: a blank blue screen for 12 seconds; and a 10 second video clip of George riding the bike with the auditory prompt. No other trainer prompts were delivered during this condition.

During the auditory prompt condition, the auditory prompts were delivered on a variable time schedule averaging continuous prompts every 12 seconds. The first condition of auditory prompts consisted of cued messages to "keep going," "pedal the bike, " "you look great riding the bike" and other encouragement prompts. In addition to the cues, the participants' names were spoken throughout the prompt schedule. These prompts "interrupted" the music provided on the tape on the 12-second variable schedule mentioned previously.

In addition to the auditory prompts and music, an additional experimental manipulation involved the comparison of continuous versus intermittent prompts. During some of the sessions, the prompts were delivered continuously (for example, on a variable 12 second schedule), during the entire leisure activity. 
During other sessions, the prompts were delivered intermittently (for example, for two minutes, the 12-second prompt schedule was in effect, and during the next two minutes, only music was given). The arrangement of two minutes with prompts and two minutes with no prompts was in effect until the men completed the leisure activity. Each participant's performance during these two variations of the auditory prompt intervention was tracked separately to ascertain if the arrangement of the prompts had an impact on leisure performance.

For George, there was an additional component of an auditory combined with a visual prompt intervention (for example, the prompts on the video). During the auditory plus visual prompt condition, George listened and watched his individual tapes with the auditory and visual prompts. No trainer prompts were delivered during this condition.

The auditory plus visual prompts were delivered on the same variable schedule as the auditory prompts, averaging continuous prompts (every 12 seconds) versus intermittent prompts (two minutes with continuous prompts every 12 seconds; two minutes with no prompts). The first condition of the auditory plus visual prompts consisted of cued messages to "keep going," "pedal the bike" and other encouragement prompts to continue while George viewed the video showing him riding his bike. His name was spoken with each prompt. These prompts showing him riding the bike "interrupted" the blank blue screen on the television. Thus, every 12 seconds a short ( 10 second) video clip showed George riding his bike, accompanied by an auditory prompt described previously. In between these auditory plus visual cues, only a blank blue screen was seen. 
The auditory plus visual prompts were also administered using an alternating schedule of continuous prompts (every 12 seconds) on some days and other days intermittent prompts (two minutes of continuous prompts every 12 seconds; two minutes with no prompts) were delivered.

\section{Experimental Design}

The effects of the auditory and/or visual prompts interspersed throughout a music and/or videotape were evaluated using a multiple baseline across participants design. A no-music baseline, a music-only baseline, and the auditory prompt intervention were implemented for 28 sessions for Marc. A nomusic baseline, a music-only baseline, the auditory prompt intervention, and the auditory plus visual prompt intervention were implemented for a total of 33 sessions for George. The baselines and the interventions were staggered across the participants to establish a relationship between the prompting procedure (musical tape with auditory cues and videotape with auditory and visual cues) and the participation levels in the leisure activity. The success of the intervention was determined by the changes in the level of participation across these conditions.

In addition to the multiple baseline design, an alternating treatment design was used for each participant to compare the effect of the continuous prompts (every 12 seconds), to the intermittent schedule (12 second prompts for two minutes, two minutes with no prompts). During the intervention, the decision to use the continuous prompts versus the intermittent schedule was established by 
random selection. Prior to each session, the cassette and videocassette tapes were randomly drawn from the box of equipment by the researcher.

\section{Behavioral Measures}

There were two behaviors measured in this study, bicycle riding and trainer assistance. For the purpose of the study, the participants were identified as engaged in bicycle riding if they completed at least one-quarter turn through a full rotation while the observer was watching. Trainer assistance was defined as any verbal or physical cueing or assistance required to keep the men on task.

The data collection procedure used to measure riding the bike and trainer assistance was a partial interval observation system. A 15-minute pre-recorded, interval tape cued an observer to assess whether or not the bike riding occurred. The researcher observed the participants for 8-seconds, and then documented their performance during a 2-second period. During each session, the participants' performance was determined based on 90 recorded intervals. The number of intervals in which any occurrence of bike riding occurred was converted to a percentage by dividing the number of intervals the behavior was observed by the total number of recording periods (90 intervals). The collected data were graphed denoting the percentage of engagement during each session. It was also recorded whether or not trainer assistance was given.

To establish interobserver agreement across all conditions and variables, data were collected by a second observer independently recording the participation during the set intervals. Both observers listened to the cueing tape together. Percentages were calculated using the number of intervals in 
agreement divided by the number of intervals of agreement plus the number of intervals of disagreement multiplied by one hundred percent. If any trainer assistance was required it was provided by the second researcher and recorded. 


\section{Chapter 3}

\section{Results}

\section{Interobserver Agreement}

Interobserver agreement on the leisure activity, riding a stationary bike, was assessed during $77 \%$ ( 20 of 28 ) of Marc's sessions. These assessments resulted in a total agreement of $97 \%$. During Marc's experimental phase, the first two days of no music baseline, the agreement was $100 \%$, and during the second experimental phase of music only there was a $99 \%$ agreement. During the auditory prompt phase, there was $95 \%$ agreement during the continuous prompt schedule, and there was $98 \%$ agreement during the intermittent prompt schedule.

For George, interobserver agreement on the leisure activity, riding a stationary bike, was assessed during $64 \%$ (18 of 33 ) of his sessions. There was $99 \%$ agreement across all of George's sessions. During the first experimental phase, the first five days of the no music baseline, there was $99 \%$ agreement, and during the music only phase, there was $100 \%$ agreement. There was $99 \%$ agreement during the continuous prompt schedule and $100 \%$ agreement during the intermittent prompt schedule of the auditory prompt phase. During the experimental phase of auditory plus visual prompts, there was a $95 \%$ agreement during the continuous prompt schedule; during the intermittent prompt schedule, there was $98 \%$ agreement. 


\section{Results of Research Question \#1}

Marc and George's performance on the leisure activity, riding a stationary bike, during the baseline and prompting conditions are found in Figure 1. A summary of their results is found in Table 2.

During Marc's no music baseline, Session 1 and Session 2, engagement in riding the bike was $32 \%$ (ranging from $24 \%$ on the lowest day to $43 \%$ on the highest day). The second baseline condition, music only with no auditory prompts, was initiated from Session 3 to Session 6. Marc's bike riding averaged $30 \%$ during this condition. The auditory prompt condition was implemented from Session 7 to Session 28. On the second day of the new condition, Marc increased his biking to an average of $45 \%$ (ranging from $8 \%$ on the lowest day to $90 \%$ on the highest day). Marc dropped on the first day of the auditory prompts (Session 7) and rebounded during the following session (Session 8). During Session 10 there was a significant decrease in participation, and on the eleventh day, physical proximity of the researcher was adjusted so that the researcher was in visual sight of the participant in order to determine if the researchers presence would cause variability in Marc's performance. Marc's engagement increased to an average of $51 \%$ during Sessions $11-13$. When the physical proximity of the researcher was adjusted to sitting beside the participant during Session 14, Marc's engagement decreased to $11 \%$. During Sessions 14-19, the researcher was positioned to the side of the participant; Marc's engagement in riding the bike increased to an average of $52 \%$. During Session 20 , the 
Figure 1.

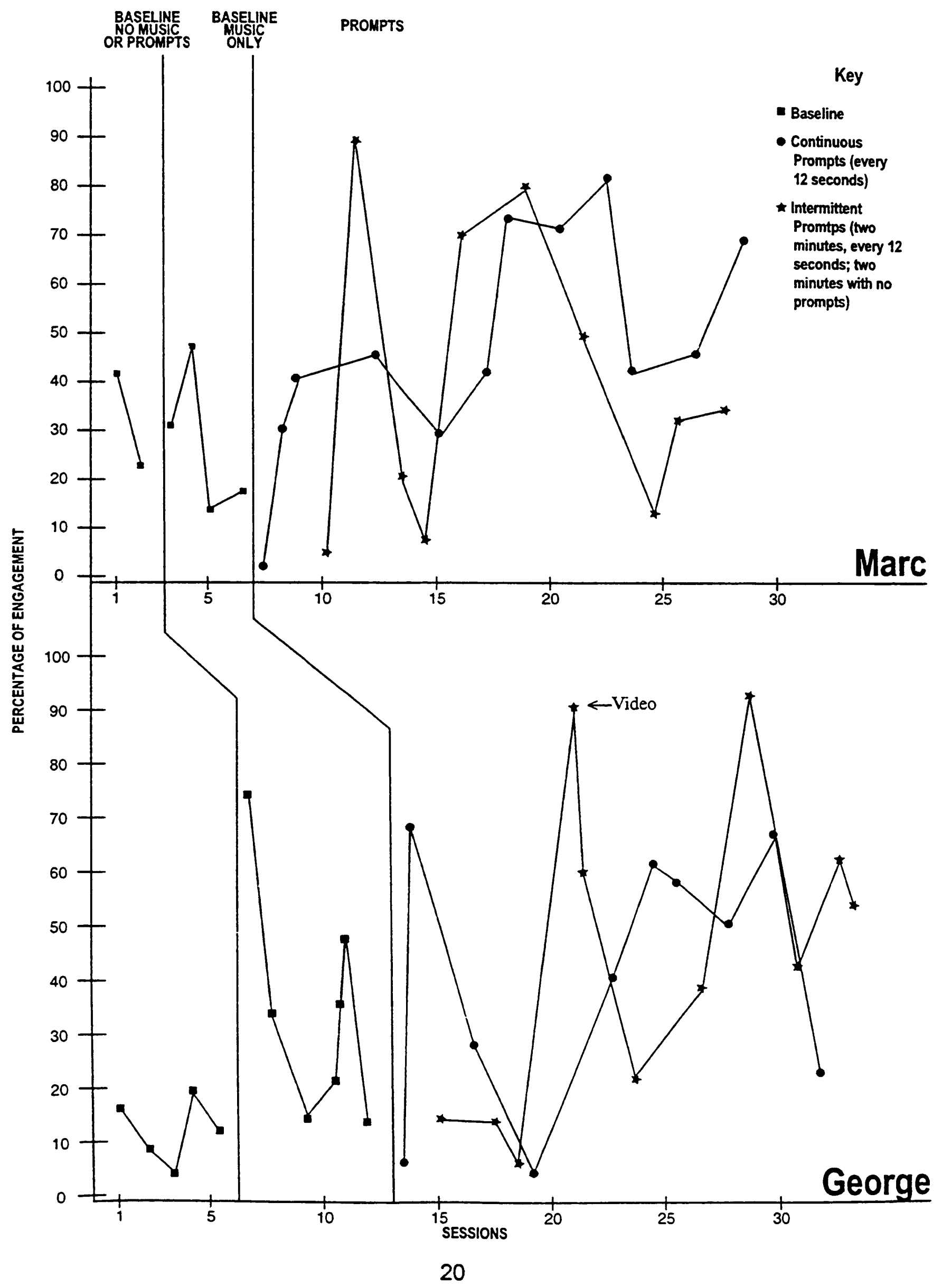


researcher's proximity was adjusted to sitting behind him. Marc's average during this adjusted condition was $48 \%$.

Table 2.

Participation Results

\begin{tabular}{l}
\hline $\begin{array}{l}\text { INTERVENTION } \\
\text { PHASES }\end{array}$ \\
\hline
\end{tabular}

\begin{tabular}{lll} 
Baseline No Music & $32 \%$ & $13 \%$ \\
$\begin{array}{l}\text { Baseline Music } \\
\text { Only }\end{array}$ & $30 \%$ & $34 \%$ \\
\hline
\end{tabular}

Continuous

Auditory Prompts

$48 \%$

$27 \%$

Intermittent

$41 \%$

$13 \%$

Auditory Prompts

Continuous

Auditory plus

Visual Prompts

N/A

$51 \%$

Intermittent

Auditory plus

N/A

$52 \%$

Visual Prompts

During George's baseline of no music, his bike riding averaged $13 \%$ (ranging from $6 \%$ on the lowest day to $20 \%$ on the highest day).

George increased to $34 \%$ during the second baseline, music only, (ranging from $12 \%$ on the lowest day to $76 \%$ on the highest day) but this increase was highly 
variable. When the auditory prompt condition was implemented from Session 13 to Session 19 , George decreased his biking to an average of $27 \%$ (ranging from $3 \%$ on the lowest day to $69 \%$ on the highest day). George's performance during the auditory prompt phase was highly variable.

During Sessions 20 and 21, George was provided with training on how to use the videotape (auditory plus visual prompts). The training consisted of listening to and watching the videotape and providing additional verbal cues to increase participation levels. Following the training sessions, the auditory plus visual prompts were implemented during Sessions 22 to 33 . George increased his biking to $51 \%$ (ranging from $21 \%$ on the lowest day to $93 \%$ on the highest day) during the sessions in which the combined prompts were used.

\section{Results of Research Question \#2}

The results showing the impact of the auditory prompt schedules for Marc are found in the last section of Figure 1 (Sessions 7 to 28). The data collected during these sessions show continuous prompts (every 12 seconds), compared to intermittent prompts (two minutes of continuous prompts every 12 seconds followed by two minutes with no prompts). For Marc, there was a minimal difference between the two prompt schedules. During the continuous prompt schedule, Marc averaged $48 \%$ (ranging from $6 \%$ on the lowest day to $83 \%$ on the highest day). During the intermittent prompt schedule, Marc averaged $41 \%$ (ranging from $8 \%$ on the lowest day to $90 \%$ on the highest day).

The results showing the impact of the two prompt schedules for George are found in the last section of Figure 1 (Sessions 13 to 19 for auditory prompts 
and Sessions 22 to 33 for auditory plus visual prompts). The data collected during these sessions show prompts delivered on a continuous schedule (every 12 seconds), compared to prompts delivered on an intermittent schedule (two minutes of continuous prompts every 12 -seconds followed by two minutes with no prompts). During the continuous auditory prompts, George averaged $27 \%$ (ranging from $3 \%$ on the lowest day to $69 \%$ on the highest day). During the intermittent auditory prompts, George averaged 13\% (ranging from $9 \%$ on the lowest day to $28 \%$ on the highest day).

The auditory prompts were combined with the visual prompts for George during Sessions 22 to 33 . During the two auditory plus visual prompt schedules, George's average increased significantly compared to the auditory prompts alone. However, there was no difference between the two prompt schedules. George averaged $51 \%$ (ranging from $22 \%$ on the lowest day to $68 \%$ on the highest day) during the continuous prompt schedule. During the intermittent prompt schedule, George averaged $52 \%$ (ranging from $21 \%$ on the lowest day to $93 \%$ on the highest day). 


\section{Chapter 4}

\section{Discussion}

The purpose of this study was to apply a self-operated prompting system to increase participation in a leisure activity and to determine whether alterations in the timing of the prompt schedules affected participation levels. The results of the study did show that the use of self-operated prompting systems resulted in some improvement in the participation of the men in the leisure activity of riding a stationary bike. With the use of the auditory prompting system, Marc showed a substantial increase from $30 \%$ to $45 \%$ in his participation of riding the stationary bike. George showed a decrease in his level of participation from $34 \%$ to $27 \%$ during the auditory prompting phase. As a result of his decrease in participation levels during the auditory prompt phase, the researcher added an additional experimental manipulation of auditory plus visual prompts (i.e. the videotape). When the auditory plus visual prompt phase was introduced, there was a substantial improvement from $27 \%$ to $51 \%$ in George's participation. The increase in participation during this study was obtained with only a limited involvement by training staff; these implications are promising in showing that with the use of similar permanent prompting strategies it may be possible for individuals with moderate to severe disabilities to participate in some leisure activities without assistance from trainers, staff or aides.

During this study, schedule changes were implemented as an extension of a previous study conducted by Davis et al. (1992), in which alternating prompt schedules were utilized to determine their effect on task fluency of vocational 
tasks in a community workshop environment. Unlike the results found in the Davis study, substantial differences were not seen in this study when the prompt schedules were changed.

During the continuous auditory plus visual prompt schedule (continuous prompts every 12 seconds), George's average for participation was $51 \%$, and during the intermittent auditory plus visual prompt schedule (continuous prompts every 12-seconds for two minutes; two minutes with no prompts), his average was $52 \%$. Marc's average for participation was $48 \%$ during the continuous auditory prompt schedule (continuous prompts every 12-seconds) and $41 \%$ during the intermittent auditory prompt schedule (continuous prompts every 12second prompts for two minutes; two minutes with no prompts). Perhaps, the insignificant differences between the two prompt schedules may be attributable to the fact that the behavior, riding a stationary bike, was a new skill. In other words, since it was necessary to train the two men to ride the stationary bike, their participation levels logically reflect a learning curve rather than a simple increase due to prompts. Also, the individuals selected for this study never achieved complete engagement in riding the stationary bike and appeared to have had limited endurance for the activity. Although there was no substantial difference between the two prompting schedules, the results did indicate the influence of the prompt systems on increasing participation in the leisure activity, riding a stationary bike. 


\section{Limitations of the Study}

Although the results of this study did show an increase in participation by the two men, there were a number of limitations to this study. First, the study was conducted under the assumption that the individuals selected to participate in the study had a repertoire of leisure activities that they enjoyed. The group home environments in which the two men lived offered a limited variety of leisure activities for individual and group involvement. In addition, the two men experienced a lot of unoccupied free time. It was discovered that the individuals needed to be introduced to and trained in various leisure activities in order for them to be able to choose a preferred activity. Not only were there limited opportunities for participation in leisure activities, but the individuals had limited skills and were therefore constrained in their participation.

Second, it was discovered that the participants had limited opportunities for socialization due, in part, to their limited social skills. The initial sessions offered the two men the opportunity to interact with the researchers, as well as learn a new skill, riding the stationary bike. The initial interactions with the researcher may have affected the variability in the participation of the two men. The prompt systems were administered on an individual basis with the primary and secondary researcher; this may have also influenced the participants' performance with the individual attention and socialization being faded during the baseline and prompt phases.

Third, the study was conducted with two men with severe mental retardation. Their varying levels of $I Q$, functioning, and limited social skills may 
have also attributed to the variability of their performance. In addition, the two men in the study had such a limited repertoire of leisure skills that it was necessary to teach activities to them. The "newness" of the activity, riding a stationary bike and their limited endurance to this activity may have attributed to the variability of their performance.

Fourth, the setting chosen for participation in riding the stationary bike may have contributed to the variability of the men's performance. Due to limited space within the group homes, the outside porches at the group homes were used as the setting for the study. This uncontrollable atmosphere allowed for distractions for the two men such as changing weather conditions, outside noises and interruptions by staff and other members of the household. It is important to note that the study was conducted during the months of February to April and the outdoor temperature ranged from 75 to 90 degrees in the afternoons.

During the initial introduction of the auditory prompt phase, the music interference may have made it difficult for the two men to decipher the auditory prompts. This factor may have had a confounding effect on the participants' performance. Another limitation was the frequency of the interventions and the duration of the study. Initially, the two men were given the opportunity to participate in 15-minute sessions five days a week. It was discovered that the two men were not willing to ride a stationary bike five days a week. A frequency of two to three days a week was found more desirable for the two men. The duration of the study may have been insufficient in establishing a significant increase in the participation levels of the two men. This study consisted of 28 
sessions for Marc and thirty-three sessions for George. Different results may have emerged over a longer prompt phase.

\section{Practical Implications}

This study extends previous research on the effect of the use of selfoperated prompting systems in increasing the independence of individuals with moderate to severe disabilities. Several studies have been conducted on the use of self-operated prompts in skill acquisition of daily living skills (Alberto et al., 1986; Briggs et al., 1990; Tyler-Trask et al., 1994; Mechling \& Gast, 1997) and to improve accuracy and fluency of vocational tasks (Davis et al., 1992). This study explored the use of self-operated prompting systems in increasing the participation of individuals with mental retardation in a leisure activity of their choice without the assistance of trainer prompts.

From this study, implications for the use of self-operated prompts for individuals with moderate to severe mental retardation should be drawn with caution due to the limited number of participants and the exploratory nature of this study. Perhaps, the most important consideration for professionals is that the use of self-operated auditory prompting systems and auditory plus visual prompting systems can be utilized to increase the independence of individuals with moderate to severe disabilities with minimal trainer assistance.

This study demonstrated that the use of self-operated prompting systems could be used effectively by individuals with mental retardation, allowing them to listen to or view a series of self-delivered prompts in an unobtrusive and normalized manner. Advantages of this intervention include its self-management 
component. This self-operated feature provided the individuals with control over their environments, and increased participation levels. Self-operated permanent prompts can be independently managed in a community setting.

The use of the Walkman and/or television and VCR offer a "normalized" prompting system that can be used in the community environment. The age appropriateness of these prompting systems also makes them desirable. Other advantages of the use of these self-operated prompting systems include the portability of the auditory systems and the discreteness of their use in a community setting.

The implications for the use of self-operated prompt systems by Therapeutic Recreation professionals are promising. Therapeutic Recreation professionals could utilize self-operated prompting systems to assist individuals in various recreational and leisure activities in institutional, group home or community settings. These self-operated prompting systems can be used to increase participation levels in various activities that promote improved physical and mental functioning, independence, and improved health and well being.

\section{Future Recommendations for Research}

Based on this study, several considerations for future research with the use of self-operated prompting systems for individuals with severe disabilities may be examined. First, the findings that self-operated auditory and auditory plus visual prompts can be utilized for individuals with severe disabilities for skill acquisition, to increase fluency of task performance, as well as to increase levels of participation should be further studied. The use of permanent prompt systems 
such as the auditory and auditory plus visual prompt systems may be an unobtrusive and "normalized" way for individuals with severe disabilities to participate independently in a variety of community settings.

Future researchers should take into account numerous factors. First, agency selection is important because establishing a professional relationship with the family and staff of the individuals that are selected for a study is vital to the success of the study. It is important to elicit the support and assistance of these individuals to help in scheduling and motivating the individuals to participate in the activities. Second, establishing the criteria for participant selection is critical. The selection of participants for a study is difficult and the individuals' diagnoses, varying level of IQs, adaptability, and levels of functioning may become a factor affecting their performance during the study.

Third, it is necessary to select an appropriate setting for the study with as few extraneous variables as possible. To eliminate many of these extraneous variables, such as weather conditions, outside noises, and interruptions by staff and other members of the household, careful selection of an isolated and controllable setting is important.

Findings in this study indicated that with the use of similar permanent prompting systems, it might be possible for individuals to function more independently in their daily lives with limited assistance from trainers or staff. In this study, it was discovered that there was variability in how this intervention affected each participant. For one man, it was necessary to adjust the auditory prompting system by adding an auditory plus visual system to increase 
participation in riding the stationary bike. The prompting conditions as well as the prompt schedules had various effects on the performance of the two men. Although this study failed to show a substantial difference between the two prompting schedules, the results were promising and indicated that the use of the prompting systems did influence the increase in participation levels. Additional research could further examine the individualized aspect of the prompting strategies, and the most beneficial prompt delivery schedules.

The therapeutic recreation profession would benefit from a more active approach in implementing programs that utilize self-management systems to assist individuals with disabilities in activities that improve overall functioning and independence. 
Agran, M., \& Martin, J.E. (1987). Applying a technology of self-control in community environments for individuals who are mentally retarded. In $\mathrm{M}$. Hersen, R.M. Eisler, \& P.M. Miller (Eds.), Progress in behavior modification, 21, 108-151.

Alberto, P.A., Sharpton, W.R., Briggs, A., \& Stright, M.H. (1986).

Facilitating task acquisition through the use of a self-operated auditory prompting system. Journal of the Association for Persons with Severe Handicaps, 11, 8591.

American Therapeutic Recreation Association (1991). Standards of Practice. Hattiesburg, MS: ATRA.

Bambara, L.M., \& Ager, C. (1992). Using self-scheduling to promote selfdirected leisure activity in home and community settings. Journal of the Association with Severe Handicaps, 17, 67-76.

Bercovici, S.M. (1983). Barriers to normalization: The restrictive management of retarded persons. Baltimore: University Park Press.

Berg, W.K, Wacker, D.P., \& Flynn, T.H. (1990). Teaching generalization and maintenance work behavior. In F.R. Rusch, Supported employment: Models, methods, and issues. Pacific Grove, CA: Brookes/Cole Publishing Company.

Brady, M.P. (1985). Synthesizing curriculum and instruction: A model for teachers in community based settings. In M.P. Brady \& P.L. Gunter (Eds.), integrating moderately and severely handicapped learners (pp. 119-136). Springfield, IL: Charles C. Thomas.

Briggs, A., Alberto, P., Sharpton, W., Berlin, K., McKinley, C. \& Ritts, C. (1990). Generalized use of a self-operated audio prompt system. Education and Training in Mental Retardation, 25, 381-389.

Browder, D.M., \& Cooper, K.J. (1994). Inclusion of older adults with mental retardation in leisure opportunities. Mental Retardation, 32, 91-99.

Browder, D.M., \& Shapiro, E.S. (1985). Applications of self-management to individuals with severe handicaps: A review. Journal of the Association of Persons with Severe Handicaps, 4, 200-208.

Collins, B.C., Hall, M., \& Branson, T.A. (1997). Teaching leisure skills to adolescents with moderate disabilities. Exceptional Children, 63, 499-512. 
Dattilo, J. (1991). Mental retardation. In D.R. Austin \& M.E. Crawford (Eds.), Therapeutic recreation: An introduction (pp.163-188). Englewood Cliffs, NJ: Prentice-Hall.

Dattilo, J. (1991). Recreation and leisure: A review of the literature and recommendations for future directions. In L.M. Meyer, C.A. Peck \& L. Brown (Eds.), Critical issues in the lives of people with severe disabilities (pp. 126-137). Baltimore, MD: Brookes.

Dattilo, J., \& Schleien, S. (1994). Understanding leisure services for individuals with mental retardation. Mental Retardation, 32, 53-59.

Davis, C.A., Brady, M.P., Williams, R.E., \& Burta, M. (1992). The effects of self-operated auditory prompting tapes on the performance fluency of persons with severe mental retardation. Education and Training in Mental Retardation, $27,39-50$.

Ferretti, R.P., Cavalier, A.R., Murphy, M.J., \& Murphy, R.(1993). The selfmanagement of skills by persons with mental retardation. Research in Developmental Disabilities, 14, 189-205.

Ford, A., Brown, L., Pumpian, I., Baumgart, D., Nisbet, J., Schroeder, J., \& Loomis, R. (1984). Strategies for developing individual recreation/leisure plans for adolescent and young adult severely handicapped students. In N. Certo, N. Haring, \& R. York (Eds.), Public school integration of severely handicapped students. Rational issues and progressive alternatives (pp. 245-275). Baltimore: Brookes.

Grossman, H. (1983). Classification in mental retardation. Washington, D.C.: American Association on Mental Deficiency.

Hoover, J., Wheeler, J., \& Reetz, L. (1992). Development of a leisure satisfaction scale for use with adolescents and adults with mental retardation: Initial findings. Education and Training in Mental Retardation, 27, 153-160.

Johnson, B.F. \& Cuvo, A.J. (1981). Teaching mentally retarded adults to cook. Behavior Modification, 5, 187-202.

Lovett, D.L., \& Haring, K.A. (1989). The effects of self-management training on the daily living of adults with mental retardation. Education and Training in Mental Retardation, 4, 306-323.

Martin, J., Rusch, F., James, V., Decker, P. \& Trytol, K. (1982). The use of picture cues to establish self-control in the preparation of complex meals by mentally retarded adults. Applied Research in Mental Retardation, 3, 105-119. 
Mechling, L.C., \& Gast, D.L. (1997). Combination audio/visual selfprompting system for teaching chained tasks to students with intellectual disabilities. Education and Training in Mental Retardation and Developmental Disabilities, 32, 138-152.

Nisbet, J., Clark, M., \& Covert, S. (1991) Living it up! An analysis of research on community living. In L. Meyer, C. Peck, \& L. Brown (Eds.) Critical issues in the lives of people with severe disabilities (pp. 115-144). Baltimore: Paul H. Brookes.

Novak, A., \& Heal, L. (1980). Integration of developmentally disabled individuals into the community. Baltimore: Paul $\mathrm{H}$. Brookes.

Peterson, C.A., \& Gunn, S.L. (1984). Therapeutic recreation program design: Principles and procedures ( $2^{\text {nd }}$. Ed.) Englewood Cliffs, NJ: Prentice Hall.

Rynders, J., \& Schleien, S. (1991). Together successfully: Creating recreational and educational programs that integrate people with and without disabilities. Arlington, TX: Association for Retarded Citizens of the United States.

Sands, D.J., Kozleski, E.B., \& Goodwin, L.D. (1992). Quality of life for workers with developmental disabilities: Fact or fiction? Career Development for Exceptional Individuals, 15, 157-177.

Schutz, R., Vogelsberg, T., \& Rusch, F. (1980). A behavioral approach to integrating individuals into the community. In A. Novak, \& L. Heal (Eds.), Integration of developmentally disabled individuals into the community. Baltimore: Paul H. Brookes Publishing Company.

Shevin, M., \& Klein, K. (1984). The importance of choice-making skills for students with severe disabilities. Journal of the Association for Persons with Severe Handicaps, 9(3), 159-166.

Sowers, J., Rusch, F., Connis, R. \& Cumming, L. (1980). Teaching mentally retarded adults to time manage in a vocational setting. Journal of Applied Behavior Analysis, 13, 119-128.

Thinesen, P., \& Bryan, A. (1981). The use of sequential picture cues in the initiation and maintenance of grooming behaviors with mentally retarded adults. Mental Retardation, 19, 246-250. 
Tyler-Trask, S., Grossi, T.A., \& Heward, W.L. (1994). Teaching young adults with developmental disabilities and visual impairments to use taperecorded recipes: Acquisition, generalization, and maintenance of cooking skills. Journal of Behavioral Education, 4, 283-311.

Wacker, D., \& Berg, W. (1983). Effects of picture prompts on the acquisition of complex vocational tasks by mentally retarded adolescents. Journal of Applied Behavior Analysis, 16, 417-433.

Wacker, D., Berg, W., Berrie, P., Swatta, P. (1985). Generalization and maintenance of complex skills by severely handicapped adolescents following picture prompt training. Journal of Applied Behavior Analysis, 18, 329-336.

Wehman, P., \& Schleien, S. (1981). Leisure programs for handicapped persons: Adaptations, techniques, and curriculum. Baltimore: University Park Press.

Wolfensberger, W. (1972). The principle of normalization in human services. Toronto: National Institute on Mental Retardation. 
APPENDIX A

PARTICIPANT CONSENT FORMS

36 


\section{Informed consent}

USE OF SELF-OFERATED AUDITORY PROMPTS TO INCRFASE CONSTRUCTIVI USE OF EREE-TIME DURING IEISURE

I, , want to participant in the zesearch pzoject listed aicore to be ccndusted through Elorida International University curing the 1397-1993 school year with manya Camper a=d Barbara kilcki. I understand that Ianya and Barbara will visit me for 6 weeks, Monday thru Eriday, anci eaci visit wil? last about 1 hour.

I uriderstand that =ise purpose of this research is to study how the lise of a personal zape player with a special tape, made just for me will help me to learn to use my free-time in a bet=er way. I wiil be abje to pick the activities.

I understand that during the risits I will wear a personal tape player with headpicases. The tape I will isten to will be made special for me. The zape will have music I picked and there will oe wcrds that will helo me do the ictirity, I pick, by myseif.

I unierstand that jie astivity I filk must be saje, ore উhat I am able to do, and one that $=$ san do by myself. I understand Tanya and

Barbara will be presert ard help me if I need heip, but, iney wart to see how well I cax do by myself.

When Tanja and Barbara write down what they learnea; trey will seep my real rame private. I will have a special code name.

I understand that I can guit the study if I really seec to and it wiIl de alright; nctody wi-i be argry at me. I understard that if I do say. "yes", it is important for me to try and stay in the stucy until the enc. I vnderstand that $\sum$ an allowed to ask questions and manya and Barbara will he happy to answer them.

If = reed to contact Tanya or Barbara; I can ask one of the Training Instructors at my home and they wiil be abie to jeip re. I will be given a copy of this consent form.

Tanya ard Barbar isave explained this consent form to tie ard I want to be a part of their study.

Participant's signizture

Date

I have explained and defined in detail the research frosedire to the ajove named individual and rave offeres him/her a cop: of this infomed consent Eorm.

Investigator's signaturs

Date

Investiqator's signature 


\section{Informed Consent}

USE OP SHF-OPARE Derenge insone

I. give my permission for Farticipant in the researci projeet listed asove to be International University diring the lg9? Incerational reguire apprcximarely six weeks with a one kour visit, five days a week.

I understand that the pliroese of this research is to study the use of self-operated auditory prompts ard their effect on frequercy and performanee of a ieisure/recreational ectivity that is selecsed by the participant.

I undorsiand that the researti procedures wiI: be as follows: fhe pazieipant will wear a personal zape player with heacpiones. The tape conterts riil irclude musie (selected by the pazticipant) with irterjected prompts which the fazicipar: wili 236 during their participation in the leisure/recreationa: activity thã tjey selected.

I understand that the rlsks involved in tis project are deternined by fie type of activity selected, but the selected activity will be in the rinimal =:sk category. The ectivity selected by the partizipant will be wirbin the range of their abiltiles ard accessible witbil their comunity. Therefore, lbe lisks lavoived will be no greater thar chose tiet exist in the perticipa.zts daily lize. There will be an observer fresent during these sessiens to record data and wino will siop the activity if the risk level increases aue to environmental and/or behavioral hazarcs.

All dato will be kept stricsly confidential and the parsicapant will je ideatified only by a cotie name.

$I$ inderstand that $I$ and/o: the participan way withdraw consent anc discontinle participarion in this resear $b$ project at any time with so negative cursequences. I Lave beeI given the right to ask questions concerning the procecure, ard any questioas heve been answered to my satisfacticn.

I understand that if I sesire further information about this ressarci, I shouid contaci Tanye Camper, Barbara Ricki or Dr. Michael Brady at sC5-398-2295. I have beer cffered a copy sf tisis irformed comsent fom.

$I$ inare read and $I$ inderstand the consent form.

İgeacy Represeräive ard Titie

Date

Earenticuardicr' 's signature

Irate

(if applicable)

Wie have expiained the reseerch prosedure to tise above ramec individiai and have ctfered $\mathrm{him} / \mathrm{her}$ a copy of the consent ferm.

Intrestigator's signature

Date

Envestigator's signature

Date 